\title{
Why some are perceived as more confident and more insecure, more reckless and more cautious, more trusting and more suspicious, than others: Enriched and impoverished options in social judgment
}

\author{
JULIE S. DOWNS \\ Carnegie Mellon University, Pittsburgh, Pennsylvania \\ and \\ ELDAR SHAFIR \\ Princeton University, Princeton, New Jersey
}

\begin{abstract}
In line with the principle of compatibility, when making social judgments, people tend to focus on personality attributes compatible with the trait under consideration. Better known, or enriched, personages are more likely to present attributes that are compatible with a particular trait than are personages about whom little is known. As a result, enriched personages are more likely to have various, sometimes even conflicting, traits attributed to them. This hypothesis is supported by a number of studies that compare the frequency with which some people are chosen as being better described by opposite trait adjectives than are others. Celebrities more often have both of a pair of opposing adjectives ascribed to them than do less well known figures. Similarly, subjects judge themselves to be better described by either of a pair of opposite adjectives than is a person who is relatively unknown in their lives. The implications for social judgment and for everyday decisions are discussed.
\end{abstract}

Classical analyses of rationality, as well as naive intuition, typically assume that people's judgments and decisions reflect their underlying beliefs and preferences. Empirical studies of decision making, on the other hand, suggest that people often arrive at a judgment or a decision, not on the basis of clearly formulated and wellestablished beliefs and preferences, but rather out of a need to formulate their values and opinions as a result of having to make a decision. Preferences and judgments, it appears, are actually constructed--not merely revealedduring their elicitation, and their construction is highly sensitive to various aspects of the task, including the ways in which options are described (e.g., in terms of gains or losses; see Tversky \& Kahneman, 1986) and the methods by which responses are elicited (e.g., through rating or through choice; see Payne, 1982; Tversky, Sattath, \& Slovic, 1988).

An influential factor in the elicitation process is the compatibility between stimulus and response. According to the compatibility principle, when stimuli and responses

This research was supported by U.S. Public Health Service Grant 1R29-MH46885 from the National Institute of Mental Health. Correspondence concerning this article should be sent to J.S. Downs, Department of Social and Decision Sciences, Carnegie Mellon University, Pittsburgh, PA 15213-3890 (e-mail: downs@andrew.cmu.edu), or to E. Shafir, Department of Psychology, Princeton University, Princeton, NJ 08544 (e-mail: shafir@princeton.edu). are mentally represented, the weight of a stimulus attribute is enhanced to the extent that it is compatible with the required response. The significance of stimulus-response compatibility has long been recognized by students of perceptual-motor performance, who have observed, for example, that a pointing response is faster than a vocal response if the stimulus is presented visually, but a vocal response is faster than pointing if the stimulus is presented in an auditory mode (Brainard, Irby, Fitts, \& Alluisi, 1962; see, also, Proctor \& Reeve, 1990, and references therein). The role of compatibility between input and output has recently been evoked by students of judgment and decision making to account for a series of surprising, yet systematic, findings. Decisions and judgments, it is suggested, are often reached by focusing on attributes that are compatible with, and thus help to formulate, the response. As a result, the weight of stimulus attributes that are compatible with the response is enhanced (Shafir, 1995; Slovic, Griffin, \& Tversky, 1990). Setting the price of a gamble, for example, has been shown to emphasize the gamble's payoff more than the probabilities do, because both the price and the payoff are in monetary units (e.g., dollars).

In this vein, consider the compatibility between the features, both positive and negative, of an option and a particular task at hand. The advantages of an option normally provide compelling reasons for selecting it, whereas the disadvantages of an option provide natural reasons for re- 
jection. Thus, the principle of compatibility suggests that positive aspects will be weighted more heavily when selecting than when rejecting, whereas negative aspects will loom relatively larger when rejecting than when selecting. Consider a situation in which one, enriched option contains both more positive and more negative features than another, impoverished option. Because the positive features of the options are weighted more heavily when choosing and their negative features are weighted more heavily when rejecting, the enriched option could be both chosen over and rejected in favor of the impoverished alternative. Shafir (1993) presented subjects with descriptions of two hypothetical vacation locations. One spot, the enriched option, was described as having plenty of sunshine, gorgeous beaches, and an ultra-modern hotel, but very cold water, strong winds, and no nightlife. The second, impoverished, alternative was said to have average weather, average beaches, average nightlife, medium temperature water, and a medium quality hotel. One half of the subjects were asked to indicate which vacation spot they would prefer; the other half were to suppose that they had reservations for both that could no longer be retained and had to indicate which of the two they would rather cancel. The information presented to the subjects was characteristic of what is typically available in choices of this type. Whereas the impoverished option seemed unremarkable yet unobjectionable on all counts, the enriched alternative had certain features (lovely beaches, sunshine, a modern hotel) that, to many subjects, made it clearly preferable and other features (cold water, winds, and no nightlife) that led many subjects to decide to reject it. Lovely beaches are more compatible with selecting than with rejecting a vacation, and strong winds are more compatible with rejection than with selection. Indeed, whether subjects were asked to select or to cancel had a significant effect on which vacation they chose: Whereas two thirds of the subjects expressed a preference for the enriched spot when asked to choose, nearly half the subjects decided to forego that spot when asked to cancel. Because the enriched option presents more compatible reasons for being selected and for being rejected, subjects are relatively more likely to select and to cancel the enriched option than its impoverished alternative. As was predicted, the enriched spot's share of being chosen and rejected (which totaled $115 \%$ ) exceeded the $100 \%$ that would be expected if choosing and rejecting were complementary.

Whereas the pattern above was observed in the context of choice, a similar logic, we suggest, applies to social judgment. People's judgments are assumed to express their beliefs and impressions, much as their choices presumably reveal their underlying preferences. Although not founded on a formal, axiomatic treatment, certain requirements of consistency that are similar to those that characterize choice apply to social judgment. Typically, if we believe that person $\mathrm{X}$ is more moral, more good-hearted, or more cooperative than person $Y$, we are not expected to think that person $\mathrm{X}$ is also more immoral, meaner, or more competitive than person Y. ${ }^{1}$ But, as in choice, the impact of compatibility on enriched and impoverished targets may lead to biased judgment.

There is substantial evidence that people see themselves as having richer, more multifaceted personalities than others (Jones \& Nisbett, 1972; Nisbett, Caputo, Legant, \& Maracek, 1973; Prentice, 1990). It has been suggested that this can result in the perception that the self possesses more traits than other people, even opposing pairs of traits, such as serious and carefree (Sande, Goethals, \& Radloff, 1988). In addition to the tendency to attribute more traits to the self than to others, Sande et al. report one study in which people are found to attribute more traits to familiar liked people than to others. These authors suggest that people ascribe more opposing traits to liked people, and to the self in particular, because this implies a richness and depth of personality and increases the perceived behavioral repertoire one may resort to in response to various situations. As these authors point out, however, it is also possible that liked people are simply better known than disliked people and, thus, make available more evidence of opposing traits.

In the present paper, we explore the role of compatibility and its impact on enriched versus impoverished options in the realm of social judgment. We do not narrow the analysis to the self-versus-others distinction, and we do not focus on liked versus disliked people. Instead, we manipulate the amount of information available about various personages, much as the foregoing analysis did in the realm of choice. Other things being equal, we suggest, a person who is better known than another represents an enriched personality, with more positive, as well as more negative, information available about him or her. Conversely, a person who is less well known constitutes an impoverished personality and is predicted to be chosen less frequently as being better described by a variety of personality traits. Assuming that adjectives, such as honest and dishonest or timid and bold, are treated roughly as opposites, the majority of subjects who attribute an adjective to one of two people are expected (in a forcedchoice context) to attribute the opposite adjective to the other person. For example, if $75 \%$ of the subjects rate Mike as more honest than Jon, approximately $25 \%$ are expected to rate Jon as more honest than Mike, and $75 \%$ are expected to rate Jon as more dishonest. Under those conditions, the percentages of subjects who consider a pe:sonage to be more moral and those who consider him to be more immoral should sum to roughly $100 \%$. If, on the other hand, respondents are biased to select the enriched option more often than the impoverished, this sum would systematically exceed $100 \%$ for the enriched personage and would add up to less than $100 \%$ for the impoverished alternative.

To illustrate, consider the following problem, which we posed to 117 Princeton undergraduate volunteers at a campus club (Neuthaler, 1992). The subjects were provided with thumbnail sketches of two men (reproduced below), both of whom were said to own and run a small business. The description of one (the enriched option, "Mike") con- 
tained numerous instances of moral and of immoral behavior, whereas the other (the impoverished option, "Jon") was described in terms that were largely irrelevant on the morality dimension. Half the subjects were asked to judge which of the two men was more moral; the other half were asked who was more immoral.

$\begin{array}{ll}\begin{array}{l}\text { Mike: } \\ \text { Collects stamps }\end{array} & \begin{array}{l}\text { Jon: } \\ \text { Plays racquetball } \\ \text { on weekends }\end{array} \\ \text { Gives money to charity } & \begin{array}{l}\text { Has three children } \\ \text { Enjoys classical music }\end{array} \\ \begin{array}{l}\text { Smokes in public } \\ \text { Does volunteer work } \\ \quad \text { on weekends }\end{array} & \begin{array}{l}\text { Reads suspense novels } \\ \text { Has two children }\end{array} \\ \text { Flirts with employees } & \text { Commutes to work } \\ \text { Hates television }\end{array}$

Mike, who exhibited instances of both moral and immoral behavior, was judged to be more moral (by $52 \%$ of the subjects) and more immoral (by $72 \%$ of the subjects) than Jon, who provided little morally relevant information. As was predicted, the tendency to select the enriched option for the two opposite adjectives exceeded the $100 \%$ total expected, were the two adjectives treated as complementary. Summing over the two conditions, Mike's share of being rated as more moral and more immoral added up to $124 \%$, whereas Jon's share added up to only $76 \%(z=$ $2.55 ; p<.05$ ).

In what follows, we use similar analyses to further explore the role of compatibility in social judgment. Study 1 presented two vignettes juxtaposing an enriched personality description with a relatively impoverished alternative. In Study 2, judgments about famous personalities, some better known and others less well known, were elicited. Study 3 employed the self as an enriched option and elicited trait attributions to the self versus a relatively unknown other. In all these studies, the subjects are found to be more likely to attribute various trait adjectives to the enriched, as opposed to the impoverished, personality, even when the adjectives are opposite in meaning. The pattern was replicated in Study 4, where the subjects were asked to list their reasons for selecting one personage over the other. As was predicted, subjects' reasons are overwhelmingly compatible with the particular adjective in question, and the enriched personage is the focus of these reasons on a significant majority of cases. The paper concludes with a discussion of the findings and their implications for everyday social judgment and decision making.

\section{STUDY 1 \\ Hypothetical Enriched and Impoverished Personages}

Following the procedure described above, the subjects were presented with the descriptions of two hypothetical people and were asked to rate which of the two, in their view, was better described by a number of trait adjectives.

\section{Method}

Subjects. The subjects were 317 Princeton undergraduate volunteers paid for their participation.

Procedure. Each of two problems presented descriptions of two hypothetical personages. In Problem 1, these were descriptions of students that were supposedly provided by a mutual friend; in Problem 2, they were descriptions of artists. These appeared in a booklet that contained other, unrelated questions and are reproduced in Table 1. In each problem, the enriched personage contained several attributes relevant to the adjectives subsequently inquired about; the impoverished personage was portrayed in nondiagnostic terms. The subjects were asked to indicate which of the two personages was better described by each of a number of adjectives. These were drawn from a list of four opposite-adjective pairs (e.g., confident-insecure), so that half the subjects received one adjective from each pair (e.g., confident), and the other half received the other (insecure). An additional, unpaired decoy adjective was presented, with the intention that it be assigned to the impoverished personage. The reason for this was twofold: (1) to verify that the subjects did not blindly favor the enriched description, given any adjective, and (2) to counteract a possible reluctance on the part of the subjects to assign the great majority of adjectives to a single personage.

For Problem 1, the decoy adjective was dishonest, chosen to match a reference to John (the impoverished option) as having once been arrested for shoplifting. The four adjective pairs used were antisocial and sociable, confident and insecure, timid and bold, and extroverted and introverted. The decoy adjective in Problem 2 was unimaginative, chosen to match a salient reference to still life paintings. The other adjective pairs used were moral and immoral, trusting and suspicious, reckless and cautious, and honest and dishonest.

\section{Results}

Figures 1 and 2 summarize the percentage of subjects who selected the enriched over the impoverished personage for each adjective in Problems I and 2, respectively. In Problem 1, the enriched personage's share of being selected across the two opposite adjectives in a pair exceeded $100 \%$ for three of the four pairs. The fourth pair (confident/insecure) was roughly equally distributed between the two personages $(97 \%$ vs. $103 \%$, for the enriched and the impoverished personage, respectively; $z=0.436$, n.s.). Over all four adjective pairs in Problem 1, the share across opposite adjectives in a pair averaged $109 \%$ for the enriched personage and $91 \%$ for the impoverished. This differs significantly from what would be expected if traits were attributed with equal likelihood to the enriched and the impoverished personages $(z=2.67, p<.005)$. Confirming our manipulation check, the decoy adjective, dishonest, was attributed to the enriched option only $2 \%$ of the time and to the impoverished option the remaining $98 \%$.

In Problem 2, the enriched personage's share of being selected across two opposite adjectives in a pair exceeded $100 \%$ for two of the four pairs; the other two pairs (trusting/suspicious and honest/dishonest) were each equally distributed between the enriched and the impoverished personages (99\% vs. $101 \%$, respectively, in both cases; $z=0.13$, n.s.). Over all four adjective pairs in Problem 2 , the share across opposite adjectives in a pair averaged $116 \%$ for the enriched personage and $84 \%$ for the impoverished personage. This differs significantly from what would be expected under the assumption that the traits are attributed with equal likelihood to the enriched 
Table 1

Descriptions of Personages Used in Study 1

Problem $1(N=253)$ : Descriptions of Students Provided by a Mutual Friend

Enriched personage description:

Your friend has told you that Bill studies entomology and ancient Greek. He lives in an apartment over PJ's, which he likes because he gets pancakes for breakfast every morning. He drives an old Jaguar, and spends most of his money to keep it going. Bill is on the lacrosse team where he ended up after getting cut from varsity crew. He was originally a member of a bicker club, but didn't like it, and is now much happier at a sign-in club. Bill is originally from Los Angeles, but moved to New York in his teens and went to boarding school just outside the city.

Impoverished personage description:

Your friend wasn't sure whether John was pre-med or pre-law. He lives in a dormitory on campus, so he doesn't drive his car very often. John likes sports and is on a varsity team. He is a member of an eating club on Prospect street. He went to a private high school, and was once arrested for shoplifting.

Problem $2(N=64)$ : Descriptions of Artists

Enriched personage description:

Chorzhanski was born in Russia in 1887, the son of a peasant farmer. He suffered a bout of polio at a young age, and was left with a pronounced limp for the rest of his relatively short life. At eleven years of age he began stealing from the local vendors to feed his family. At age fifteen he stole his first canvas upon which he would later paint his most famous work, "The Feast of the Devils." He always painted in the seclusion of an abandoned shack behind his father's farm, and no one except his mother ever saw his paintings until after his death in 1917 at the age of 29.

Impoverished personage description:

Zhivouli was born in the late nineteenth century. His works include a series of portraits, as well as an assortment of still life paintings. He was best known for his painting "Oranges and an Apple." He died at age 57, after which most of his paintings were sold at public auction to private collectors. Only one of these paintings is now in the United States, as most of them remained in Europe or were destroyed during the war.

and impoverished personages $(z=2.47, p<.01)$. As before, the decoy adjective, unimaginative, was attributed to the enriched option only $4 \%$ of the time and to the impoverished option the remaining $96 \%$, confirming that the subjects were not blindly assigning all the adjectives to the enriched personage.

\section{STUDY 2 \\ Famous Enriched and Impoverished Personages}

As was illustrated in Study 1, the presentation of information in the form of enriched and impoverished options can lead subjects to focus selectively on enriched alternatives, those that provide more information compatible with the task at hand. In the next study, we explore this discrepancy in judgments concerning real-world, wellknown personages.

\section{Method}

Subjects. The subjects were 200 volunteers, recruited in a public setting in Berkeley, California, and paid for their participation.

Procedure. As in the previous study, the subjects compared enriched and impoverished personages on three dimensions consisting of opposite adjective pairs. In this experiment, the personages were famous people, and only their names, with no descriptions, were provided. Six pairs of names were used. The enriched alternative in each pair was a well-known public figure, such as Ronald Reagan or Woody Allen. The impoverished personage was widely recognized, but a person about whom most people knew very little, such as John Major or Federico Fellini. Names were paired by similar occupations to make the comparisons more natural (see Table 2). Each subject was presented with three of the six pairs of names and with three adjectives (one from each of three opposite adjective pairs: moral/immoral, reckless/cautious, and confident/insecure.) For each adjective, the subjects selected the person in each pair who was better described by that adjective.

Manipulation check. Following the task above, the subjects rated their familiarity with the 12 personages in the study on a 5-point scale, from very familiar to not very familiar, plus a 0 option to indicate complete lack of familiarity. As was expected, the enriched personages were rated as being significantly more familiar than their impoverished counterparts $(p<.001$ in all cases; see Table 2$)$.

\section{Results}

As before, the subjects tended to choose the enriched option more frequently than the impoverished, yielding a total share over opposite adjective pairs that was significantly greater than $100 \%$ for the enriched personages (see Figure 3). Whereas 4 (out of 18) adjective pairs summed below $100 \%$ for the enriched personage, the majority of enriched personage ratings across adjective pairs exceeded $100 \%$ (sign test, $p<.05$ ). The average sum over opposite adjective pairs for the enriched personages was $108 \%$, with an average sum of $92 \%$ for the impoverished counterparts $(z=2.71, p<.01){ }^{2}$ 


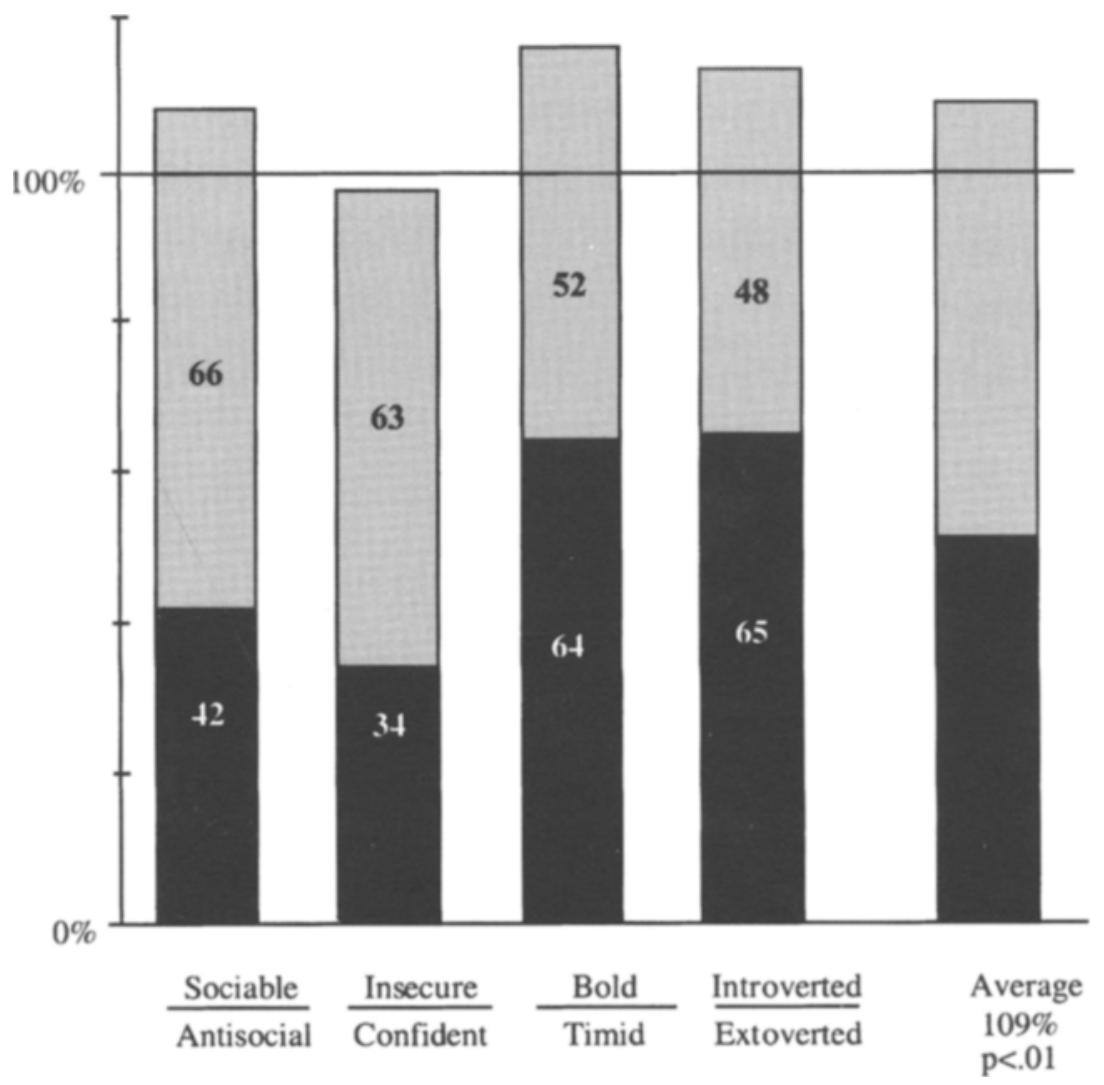

Figure 1. Percentage of subjects rating the enriched option (Bill) as being better described by each of two opposite adjectives in Problem 1. Each bar represents the sum of the two adjectives identified below it. Percentages are reported inside the bars. The "Average" bar represents the average sum across all adjective pairs.

\section{Discussion}

Among the enriched personages, only one (Simon) averaged below $100 \%$ over opposite adjective pairs; all the others exceeded $100 \%$. This occurred despite the fact that the subjects held strong opinions about some of the personages, who, as public figures, are often stereotyped. Thus, Whoopi Goldberg was clearly seen as confident $(90 \%)$ and not insecure $(20 \%)$, as compared with Vicki Lawrence, but the sum of her ratings nevertheless exceeded $100 \%$. Likewise, Woody Allen was seen as insecure $(88 \%)$ and not confident (only $31 \%$ ), as compared with Fellini, but his ratings on these dimensions nonetheless totaled $119 \%$.

Such extreme judgments, however, can also lead to an occasional failure of our prediction. In the foregoing, as well as the following, studies, the adjectives we used were selected to cover a range of personality traits. Some traits, however, prove to be more applicable to some personages than to others. In Study 2, for example, José Canseco was judged as resolutely not cautious $(5 \%)$ and Paul Simon as resolutely not reckless $(8 \%)$. Similarly, in Problem 2 of Study 1, Chorzhanski was seen as not very trusting or honest. Some adjectives apply very poorly to certain personages, whatever their level of familiarity. Consequently, we do not observe the expected pattern on each and every pair of adjectives underlying judgment. Over a number of such adjective pairs, on the other hand, we expect the trend to be manifested. In this vein, it is worth noting that, whereas certain individual adjective pairs fail to exhibit the predicted pattern, an accumulation of adjective pairs, as was observed in Study 2, tends to exhibit a total of at least $100 \%$ for most enriched personages.

\section{STUDY 3 \\ The Self as Enriched Personage}

The tendency to select enriched over impoverished alternatives was documented in situations in which relevant information was explicitly presented to subjects (Study 1) and in situations where information was retrieved from memory (Study 2). It is, apparently, the relative amount of available information, whether presented or recalled, that underlies the enriched/impoverished discrepancy. As was mentioned earlier, this discrepancy also helps to explain patterns of judgment concerning the self versus others. In the following study, we turn to what is likely to be the most enriched option of all, oneself (cf. Kihlstrom \& Klein, 1994). 


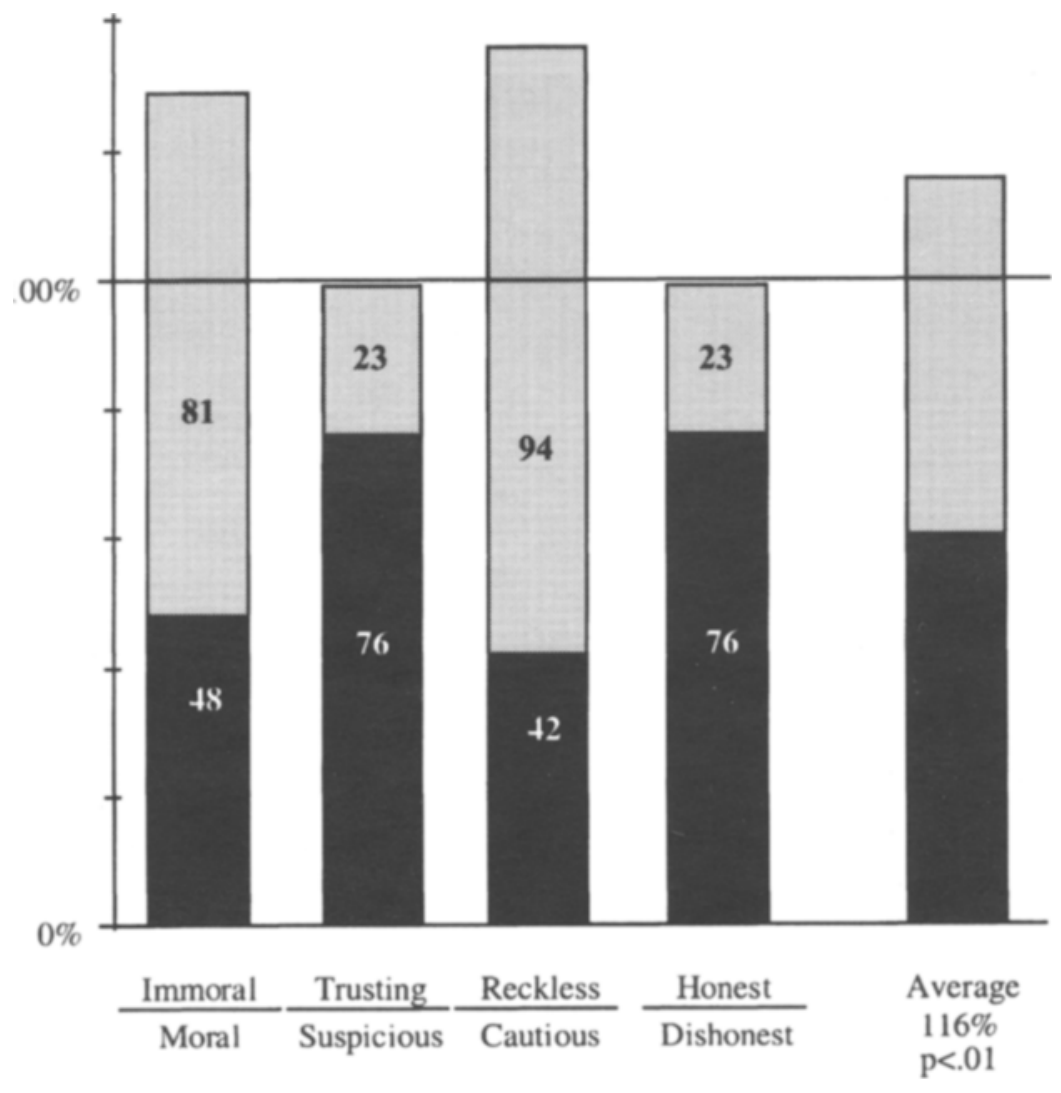

Figure 2. Percentage of subjects rating the enriched option (Chorzhanski) as being better described by each of two opposite adjectives in Problem 2. Each bar represents the sum of the two adjectives identified below it. Percentages are reported inside the bars. The "Average" bar represents the average sum across all adjective pairs.

\section{Method}

Subjects. The subjects were 244 Princeton undergraduate volunteers paid for their participation.

Procedure. The subjects filled out a questionnaire in a booklet format, alongside other, unrelated questions. For each of a number of adjectives, they were asked to indicate who was better described by the adjective: they or their resident advisor (RA). ${ }^{3}$ Thus, the subjects served as their own enriched option, and the RA, a person whom they could identify but typically knew little about, served as the impoverished alternative. Eight pairs of adjectives were used, all considered to be antonyms in pretesting (Figure 4). Half the subjects received one adjective from each pair; the other half received the other.

\section{Results}

As is shown in Figure 4, the subjects were more likely to describe themselves, the enriched option, as being more honest as well as more dishonest, more timid and more bold, more moral and more immoral, and more suspicious and more trusting than their RA. The tendency to choose oneself as being better described by the two antonyms in a pair added up to more than $100 \%$ in seven of the eight pairs $(p<.55$, sign test). On average, the subjects chose themselves as being better described by either of the antonyms in an adjective pair $109 \%$ of the time and their advisor only $91 \%$ of the time $(z=3.65, p<.001)$.

\section{Discussion}

As was predicted, the subjects appear to have found more compatible evidence in their knowledge about the self than about their relatively little-known RA. This is consistent with Sande et al.'s (1988) studies showing a greater attribution of traits to the self than to others. In further agreement with those studies, we did not observe a systematic tendency to see oneself in particularly positive (or negative) terms, as compared with another person, although other research (cf. Taylor \& Brown, 1988) has shown a bias to see oneself in positive terms. Peopie often think they are smarter than average, better drivers than average, and so on. The subjects in our study, however, were not biased to see themselves as being better described by positive rather than negative terms, as compared with their RA. This may be partly due to the fact that RAs are generally seen in a positive light. In addition, people appear to be less likely to compare themselves favorably with a concrete, even if little known, individual than to see themselves as better than a vague average (Alicke, Klotz, Breitenbecher, Yurak, \& Vredenburg, 1995; Klar, Medding, \& Sarel, 1996). In the abstract, people tend to consider themselves as being above average; but in comparison with a specific other, instances compatible 
Table 2

Average Familiarity Ratings for Enriched and Impoverished Personages in Study 2, on a Scale From 0 (Never Heard of Him or Her) to 5 (Very Familiar)

\begin{tabular}{lcllc}
\hline \multicolumn{1}{c}{ Enriched } & & & \multicolumn{2}{c}{ Impoverished } \\
\cline { 1 - 2 } \cline { 5 - 5 } Personage & Rating & & Personage & Rating \\
Ravid Letterman & 3.93 & & Kathy Lee Gifford & 2.23 \\
Wonald Reagan & 4.51 & & John Major & 2.66 \\
Woody Allen & 4.15 & & Federico Fellini & 1.77 \\
José Canseco & 2.91 & & Tony Gwynn & 1.41 \\
Paul Simon & 3.91 & & Robert Smith & 2.18 \\
Whoopi Goldberg & 4.04 & & Vicki Lawrence & 1.80 \\
\hline
\end{tabular}

Note-All pairwise differences were significant at $p<.001$.

with a particular trait (negative as well as positive) are more likely to arise in the context of a person's own evaluation, yielding judgments that highlight the self.

\section{STUDY 4 \\ Reasons for Choosing Enriched and Impoverished Personages}

The foregoing studies document the tendency to choose enriched personages more frequently than impoverished personages when judging which is better described by a variety of adjectives. It is suggested that enriched personages are more likely to present judgment-compatible information than are their impoverished counterparts. The compatibility hypothesis has received further support in decision-making studies in which subjects are asked to list which option features were most important to their decision. Subjects making preference judgments designated more positive features as being important, whereas those making rejection decisions designated more negative features (Houston \& Weeks, 1999). In the following study, we further explore the role of compatibility as regards enriched versus impoverished personages in social judgment by eliciting subjects' rationales for designating either personage as being better described by the adjective in question.

\section{Method}

Subjects. The subjects were 69 volunteers, recruited around Carnegie Mellon University and paid for their participation.

Procedure. Famous personages' names were pretested in order to construct 12 enriched/impoverished pairs that were at least minimally familiar to most people. All the pairs satisfied the following criteria in pilot testing: (1) more than $80 \%$ of the respondents had heard of the impoverished personage; (2) the mean difference between personages was at least 1 point on the familiarity scale; and (3) fewer than $20 \%$ rated the impoverished personage as

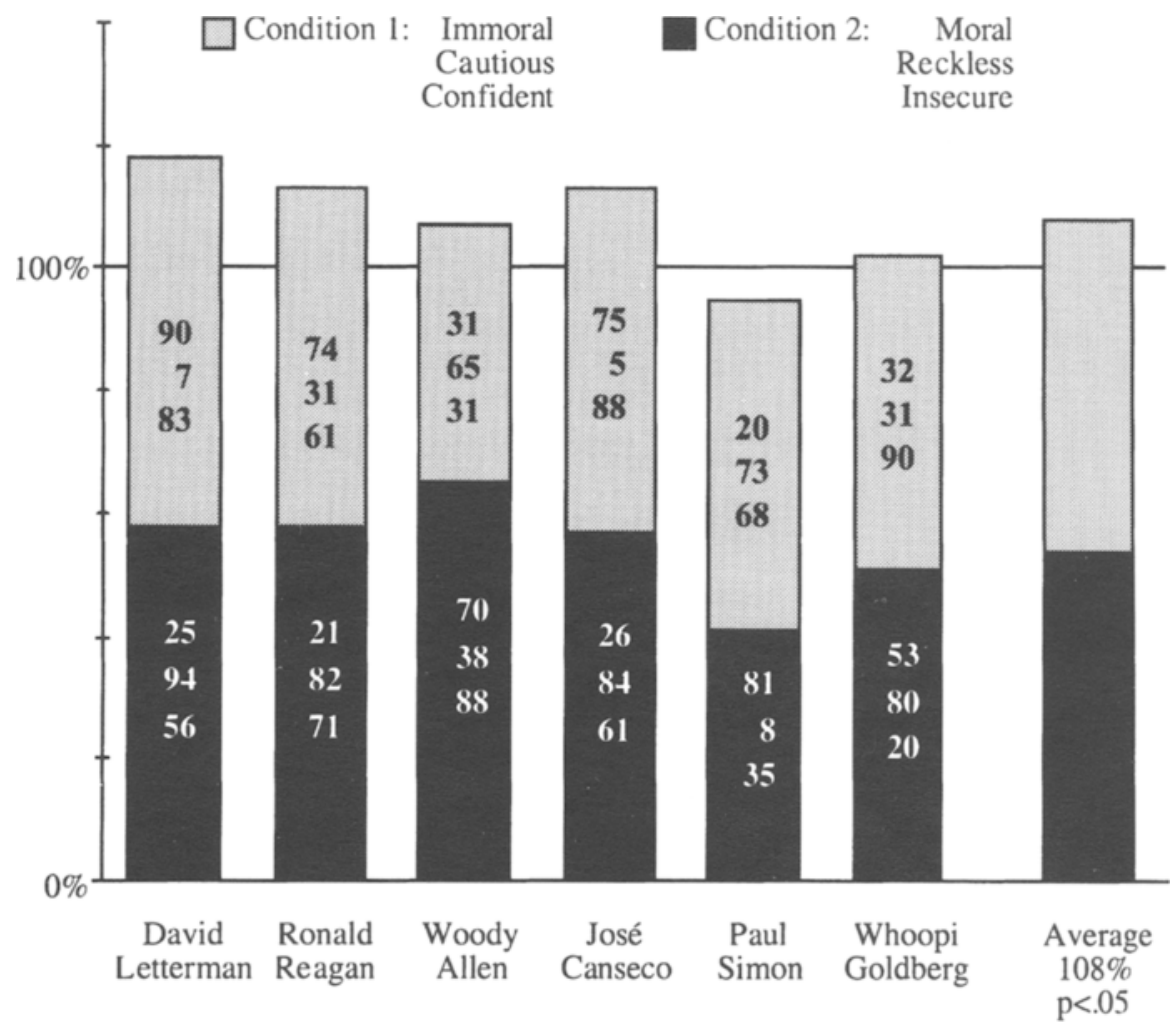

Figure 3. Percentage of subjects rating the enriched personality as being better described by each of two opposite adjectives in Study 2 . Each bar represents the average sum of the two adjectives over all three adjective pairs. Percentages are reported inside the bars in same order as appears in legend. The "Average" bar represents the average sum across all adjective pairs. 


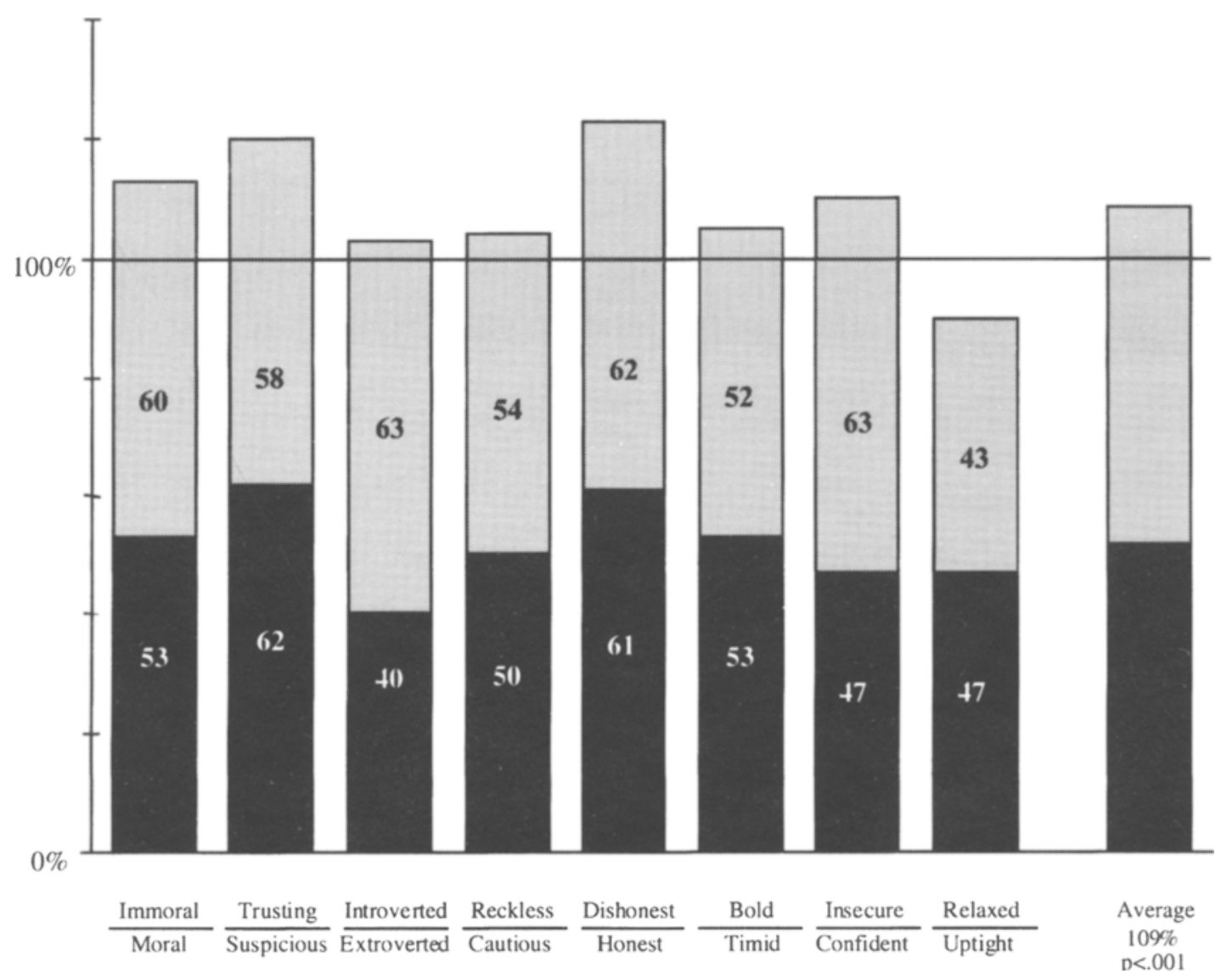

Figure 4. Percentage of subjects rating themselves as being better described by each of two opposite adjectives in Study 3. Each bar represents the sum of the two adjectives identified below it. Percentages are reported inside the bars. The "Average" bar represents the average sum across all adjective pairs.

being more familiar than the enriched. The 12 personage pairs included singers, politicians, royalty, sports figures, and talk show hosts. ${ }^{4}$ Each subject was presented with all the pairs. For each pair, the subjects were presented with a descriptive adjective (selected from among those in earlier studies; see Table 3 ) and indicated which personage was better described by the adjective in question.

Following each judgment, the subjects were prompted to "please describe briefly any reasons or considerations that made you choose the person you did and not the other." Half the subjects gave their reasons immediately following each judgment. The other half made all the judgments before they were instructed to give reasons. (This was done to verify that providing reasons did not alter the actual judgments.)

Manipulation check. Upon completion of the above task, the subjects rated their familiarity with all 24 personages on a 6-point scale: 0 indicating that the subject had never heard of the person, and 1-5 ranging from not very familiar to very familiar. As was expected, the enriched personages were rated as being significantly more familiar than their impoverished counterparts $(p<.0001$, in all cases; see Table 3).

\section{Results}

Those subjects who listed their reasons following each choice and those who listed their reasons after having made all the choices did not differ in the choices they made or in the reasons they provided. The data were collapsed across this condition for all the analyses that follow.

Choices. The subjects chose the enriched personages significantly more often than the impoverished, for a total average share over opposite adjective pairs of $110 \%$ for the enriched personages and $90 \%$ for the impoverished $(z=$ 2.87, $p<.01$; see Figure 5).

Reasons. Two naive raters independently coded which personage was referred to by the reasons provided, with $95 \%$ reliability in their coding. A third naive rater coded which adjective (the one presented or its complement) figured more prominently in those reasons. This rater was provided only with the subjects' stated reasons and did not know which of the two adjectives the subject had seen. For some choices, the subjects failed to provide any reasons, either writing nothing $(12 \%)$ or indicating that they did not know (19\%). Where reasons were provided, $4 \%$ referred to both personages, and the rest exhibited a clear tendency to refer to the enriched personage more often than to the impoverished one $(74 \%$ vs. $26 \% ; z=12.97$, $p<.0001)$. This was partly mitigated by the choice made. 
Table 3

\begin{tabular}{|c|c|c|c|c|}
\hline \multicolumn{5}{|c|}{$\begin{array}{l}\text { Table } 3 \\
\text { Average Familiarity Ratings for Enriched and Impoverished } \\
\text { Personages in Study } 4 \text { on a Scale From } 0 \text { (Never Heard of Him or Her) } \\
\text { to } 5 \text { (Very Familiar), Along With the Adjective Pairs Used }\end{array}$} \\
\hline \multicolumn{2}{|l|}{ Enriched } & \multicolumn{2}{|c|}{ Impoverished } & \multirow[b]{2}{*}{ Adjective Pair } \\
\hline Personage & Rating & Personage & Rating & \\
\hline Elton John & 3.87 & Don Henley & 2.09 & uptight/relaxed \\
\hline Ronald Reagan & 0 & John Major & 1.86 & confident \\
\hline Cher & 3.86 & Toni Braxton & 2.66 & suspicious/trusting \\
\hline Princess Diana & & & 1 & \\
\hline Madonna & & & 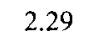 & honest \\
\hline Benjamin Netanyahu & 1.84 & Ehud Barak & 0.78 & cautious/reckless \\
\hline Mike Tyson & 3.68 & Joe Frasier & 2.39 & extroverted/introverted \\
\hline Bob Dole & 3.57 & Jack Kemp & 2.36 & suspicious/trusting \\
\hline Whitney Houston & 3.68 & Anita Baker & 1.96 & timid/bold \\
\hline Hillary Clinton & 4.04 & Tipper Gore & 2.82 & antisocial/sociable \\
\hline Nelson Mandela & 3.0 & Tony Blair & 1.78 & extroverted/introverte \\
\hline Oprah Winfrey & 3.88 & Sally Jesse Raphael & 3.17 & suspicious/trusting \\
\hline
\end{tabular}

Note-All pairwise differences were significant at $p<.001$.

When the impoverished personage was selected, the reasons were equally likely to refer to the person selected $(49 \%)$ as to the one not selected $(51 \%)$. On the other hand, when the enriched personage was selected, the reasons provided were overwhelmingly more likely to focus on the selected person $(94 \%)$ than on the person not selected $\left(6 \% ; \chi^{2}=174, p<.001\right)$. Twelve percent of the reasons that the subjects provided were deemed to be either irrelevant or equally attributable to either adjective in a pair. Of the remaining reasons, averaged over opposite adjectives in a pair, $84 \%$ were judged to be more compatible with the adjective under consideration, and $16 \%$ were judged to be more compatible with the opposite adjective $\left(\chi^{2}=247, p<.001\right)$.

\section{Discussion}

The respondents in the foregoing study were overwhelmingly more likely to list reasons that were compatible with the adjective under consideration, and these reasons were significantly more likely to be assigned to the enriched than to the impoverished alternative. This is consistent with the notion that enriched personages provide more judgment-compatible information than do their impoverished counterparts. This pattern further agrees with earlier research on compatibility in decision making, wherein subjects were shown to be significantly more likely to list features that were compatible with the task at hand, and these features were more likely to be found in the enriched than in the impoverished option.

As before, the effect varied across specific adjectives and personages. One possible explanation is that individuals are differentially familiar with the personages under consideration. If, for example, respondents are equally familiar with the enriched and the impoverished personages, they would not be expected to preferentially select one over the other. We sorted the pairs in the two studies that included familiarity ratings (Studies 2 and 4 ) and found that the average difference in familiarity between enriched and impoverished personages was posi- tively correlated with the tendency to choose the enriched option $(r=.57, p<.11$, for Study 2 , and $r=.63, p<.10$, for Study 4). Although these correlations are based on few observations and are, thus, only marginally significant, they support the notion that familiarity differences play an important role in the preferential selection of enriched personages.

A selective and occasionally idiosyncratic focusing on reasons or arguments in judgment may also explain some of the variability observed in our data. Reminiscent of the patterns that ran counter to our prediction in the earlier studies, in Study 4, Hillary Clinton (the enriched alternative) was seen as being slightly more antisocial (55\%) but far less social $(20 \%)$ than Tipper Gore, thus summing up to less than $100 \%$. The respondents may have felt that Hillary Clinton's seemingly social behavior was politically motivated and, thus, not authentic, a consideration that was less salient when they gauged her antisocial tendencies. In this vein, a study of the perceived consequences of risky behaviors, for example, found persistent asymmetries in the perceived consequences of accepting and rejecting a risky action. Considerations such as being liked by friends appear to be less salient when youths consider using marijuana than when they consider declining it (Beyth-Marom, Austin, Fischhoff, Palmgren, \& JacobsQuadrel, 1994). Because of such asymmetries, BeythMarom et al. suggest, it may be hard to understand people's tendency to take a particular action, if one fails to elicit the perceptions associated with not taking it. Similarly, in social judgment, it may be hard to understand people's impressions of someone's specific traits, if one fails to elicit the perceptions associated with seemingly conflicting traits.

\section{GENERAL DISCUSSION}

As was the case in the context of choice, the impact of compatibility on enriched and impoverished targets was shown to lead to biased judgment. Other things being 


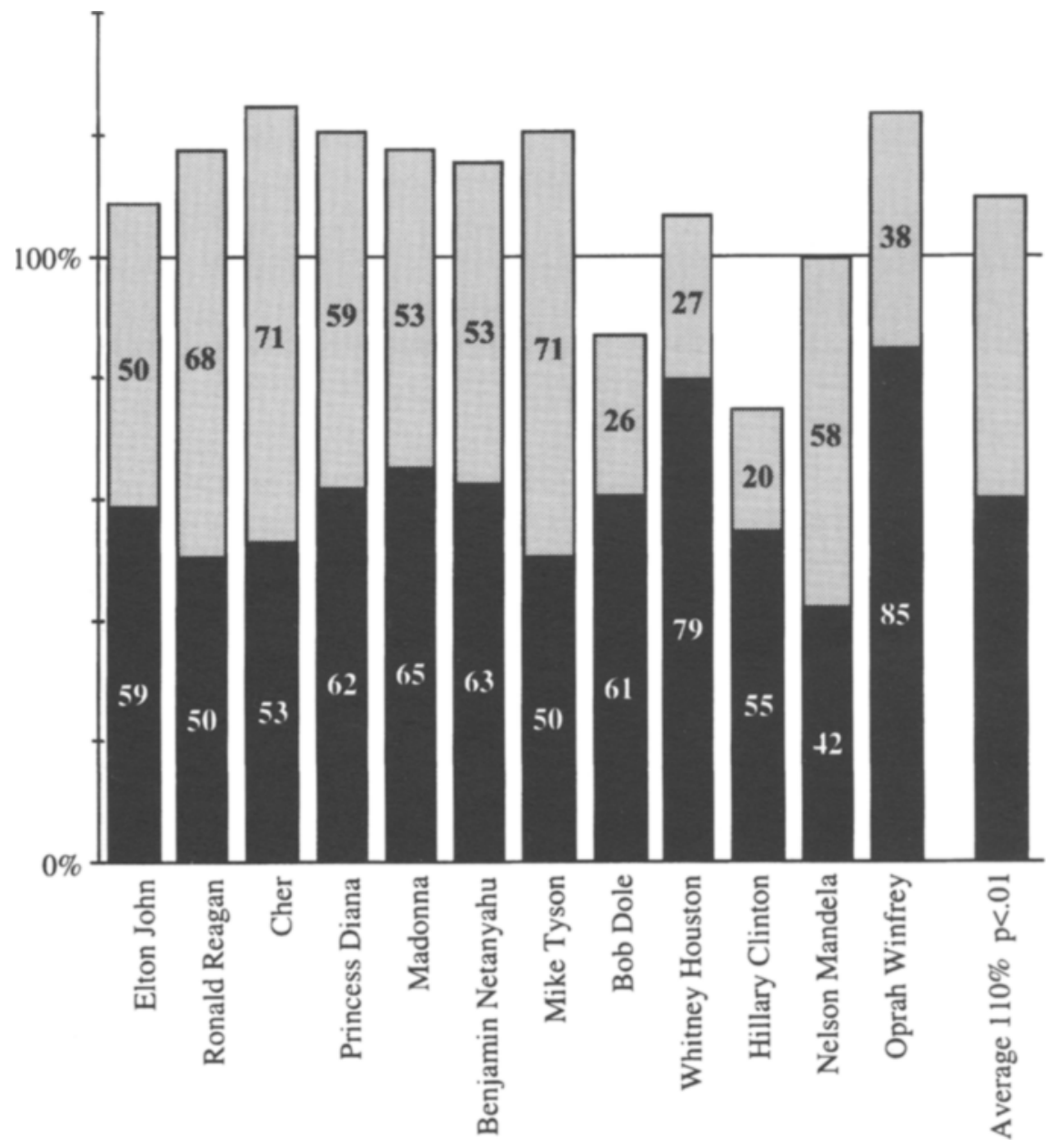

Figure 5. Percentage of subjects rating the enriched personality as being better described by each of two opposite adjectives in Study 4. Each bar represents the sum of the two adjectives in a pair, with percentages reported inside the bars. The "Average" bar represents the average sum across all adjective pairs.

equal, the studies above show that people are more likely to consider a more familiar personage as being better described by various opposite adjectives than is an impoverished personage, about whom less is known. To what extent are people aware of and comfortable with this tendency?

When we asked the subjects whether they thought that a person could be "both more moral and more immoral than another," $69 \%$ thought that this was "sometimes" or "often" possible. Asch and Zukier (1984) found that people can resolve discordant adjective descriptions quite effortlessly, using techniques such as segregation, where discordant adjectives are attached to different regions of the described person's life. To get a sense of the ease with which people actually attribute opposing adjectives to a single personage when doing so is transparent, we presented subjects with two adjective pairs used in Study 3, only this time we asked each subject about both opposite adjectives on a single page. In particular, the subjects $(N=82)$ were asked who they thought was more moral (or honest), they or their RA, as well as who they thought was more immoral (or dishonest), they or their RA. Averaged over the two adjective pairs, the subjects considered themselves to be more moral/immoral and more honest/ dishonest $105.5 \%$ of the time in this transparent manipulation (as compared with an average of $118 \%$ for the same traits in the between-subjects version). Overall, the tendency to choose oneself as being better described by either of opposite adjectives was weakly present (but, summed up, not significantly different from $100 \%$ ) in this transparent manipulation. ${ }^{5}$ Although subjects believe that one person may sometimes be better described than another by both opposite adjectives in a pair and occasionally are willing to assign such ratings, the tendency 
to select a single personage for both opposite adjectives is, nevertheless, significantly greater when such an assignment is not transparent.

It is worth pointing out that the bias observed in our studies resides not merely in one personage being selected more frequently than another, but in the persistent tendency to select the personage with whom the subject happens to be more familiar. Other things being equal, an enriched personage is predicted to be chosen more frequently as being better described by a variety of personality traits then an impoverished personage, simply because the enriched personage presents more features that are compatible with the trait under consideration. Furthermore, in the process of formulating their opinion, subjects may then be inclined to generate additional reasons or arguments that are compatible with and help to justify the emerging response (Pennington \& Hastie, 1988; Shafir, Simonson, \& Tversky, 1993; Slovic, 1990; Tetlock, 1992).

The tendency to evoke compatible information is reminiscent of the work of Snyder and his colleagues on hypothesis confirmation biases in social judgment (Snyder \& Cantor, 1979; Snyder \& Swann, 1978). That work documented people's tendency to evoke information, from memory and other data, that is compatible with the hypothesis under consideration. When deciding whether a person is extroverted, for example, subjects seek out memories or information indicating extroversion; when contemplating the possibility that the same person is introverted, subjects seek out memories indicating introversion. Two possible accounts are proposed for this phenomenon. First, it could reside in the retrieval of information, with the hypothesis that is tested acting as a prime, thus making compatible items easier to retrieve (cf. Tversky \& Kahneman, 1973). Alternatively, greater relevance might be attached to confirming evidence than to disconfirming evidence.

Our data suggest that the first account cannot be the sole explanation, since some of our studies did not rely on memory retrieval. As for the second account, it appears that a differential weighting applies not only to evidence used to evaluate hypotheses, but also to information used to construct preferences and judgments. Note that the subjects in our studies were not presented with a hypothesis to confirm. They were not asked, for example, whether person $X$ was insecure. Rather, we simply asked who was more insecure, person $\mathrm{X}$ or person Y? Because there is no hypothesis to be confirmed, simple confirmation bias cannot predict which person will be selected. Rather, the present data are predicted by the assumption that compatible items loom larger, along with an imbalance in the availability of compatible items between the enriched and the impoverished alternatives. The enriched alternative provides more compatible items and, thus, proves more likely to be selected.

The notion that our judgments rely selectively on options' positive and negative aspects has some interesting implications. Consider, for example, the workings of se- lection committees and assume a pool of contestants, all of whom have their faults and their good qualities, only some have more of both than do others. During a weedingout process, committees are strongly invested in eliminating those candidates whom they perceive as having significant faults (with less emphasis on their good qualities). In such situations, negative aspects will loom large, and enriched candidates, those who present more reasons to oppose them, are likely to be rejected. If, instead of weeding out, a committee sets itself the task of selecting the winner, candidates' positive qualities will loom large, and the enriched candidates, those who present more reasons to choose them, are likely to be selected. All else being equal, therefore, enriched candidates have a better chance, relative to their impoverished competitors, when candidates are being chosen than when they are being rejected. Huber, Neale, and Northcraft's (1987) study of personnel selection decisions seems to be consistent with this interpretation. These researchers presented subjects with actual resumes and letters of application received by a firm in response to an advertisement in a local newspaper. The subjects were asked to list the names of all the applicants they would accept for an interview or, instead, to list those they would reject. Resumes are likely to be biased toward candidates' strengths, with few weaknesses explicitly stated. In deciding which candidates to accept, subjects select those with the most impressive qualities; but when rejecting candidates-hence, focusing on their weaknesses-subjects may find little to focus on and, thus, end up rejecting relatively few. Indeed, it was found that significantly more candidates made it to the job interview under the rejection than under the acceptance frame.

The judicial system involves similar character judgments. The determination of a defendant's innocence or guilt, for example, is likely to be influenced by the jury's opinions about his or her character. Asked to assess the likelihood that a defendant is guilty, jurors are likely to focus on negative characteristics indicative of guilt, relative to a greater reliance on positive features, were they to consider the likelihood of innocence. Paradoxically, such biased focusing may prove more influential when more is known about the defendant, rather than less.

People make character judgments not only in legal or professional settings, but also in everyday interactions with others. The traits people look for in others are shaped by expectancies, stereotypes, and other sources of potentially inaccurate or biased information. Once specific traits are contemplated, however, they are more likely to be observed than not and are most likely to be found in individuals or groups we know more about (accurately or inaccurately). In addition, we may be more confident about judgments regarding well-known entities, merely because we are able to amass more confirmatory (while discounting disconfirmatory) evidence. Such patterns can exacerbate the perpetuation of stereotypes, especially as they gain notoriety. Paradoxically, as a stereotyped group becomes more familiar, more confirmatory instances of the stereotype may be found. 
Familiarity can play an influential role in social judgment even when it seems unrelated to the task at hand Thus, the imbalance in information generated by enriched versus impoverished alternatives can significantly influence judgments concerning the perceived character of a politician or the relative merit of parents to be awarded custody of a child (Shafir, 1993). The lability of judgments that arises from compatibility, as from other framing and elicitation effects, raises difficult questions concerning the assessment of beliefs and preferences. We typically think of people's judgments as reflecting their underlying beliefs and values and regard logically equivalent elicitation methods as roughly neutral means by which to translate these subjective beliefs into explicit and meaningful expressions. In this regard, the present findings may not be easily reconcilable with our own intuitions. Although compatibility can have a powerful effect on the expression of attitudes, people are generally unaware of its influence, operating, as it does, at an elementary level of information processing (see Shafir, 1995, and Slovic et al., 1990, for discussions). An awareness of this phenomenon, therefore, is unlikely to make it disappear but may explain otherwise puzzling attitudes and help to anticipate and, thus, minimize its effects in situations where it is most likely to appear.

\section{REFERENCES}

Alicke, M. D., Klotz, M. L., Breitenbecher, D. L., Yurak, T. J., \& VREDENBURG, D. S. (1995). Personal contact, individuation, and the better-than-average effect. Journal of Personality \& Social Psychology, 68, 804-825.

AsCH, S. E., \& ZUKIER, H. (1984). Thinking about persons. Journal of Personality \& Social Psychology, 46, 1230-1240.

Beyth-Marom, R., Austin, L., Fischhoff, B., Palmgren, C., \& JacobsQuAdrel. M. (1994). Perceived consequences of risky behaviors: Adults and adolescents. Developmental Psychology, 29, 549-563.

Brainard, R. W., Irby, T. S., FitTs, P. M., \& Alluisi, E. (1962). Some variables influencing the rate of gain of information. Journal of Experimental Psychology, 63, 105-110.

HOUSTON, D. A., \& WEEKS, M. (1999). Should I decide which alternative I prefer . . or which alternative I reject? Feature salience in choice dilemmas [Working paper]. University of Memphis, Department of Psychology.

Huber, V., Neale, M., \& Northcraft, G. (1987). Decision bias and personal selection strategies. Organizational Behavior \& Human Decision Processes, 40, 136- 147.

JONES, E. E., \& NiSBETT, R. E. (1972). The actor and the observer: Divergent perceptions of the causes of behavior. In E. E. Jones, D. E. Kanouse, H. H. Kelley, R. E. Nisbett, S. Valins, \& B. Weiner (Eds.), Attribution: Perceiving the causes of behavior (pp. 79-94). Morristown, NJ: General Learning Press.

KinlSTROM, J. F., \& KLEIN, S. B. ( 1994). The self as a knowledge structure. In R. S. Wyer \& T. K. Srull (Eds.), Handbook of social cognition (pp. 153-208). Hillsdale, NJ: Erlbaum.

KLAR, Y., MEDding, A., \& SAREL, D. (1996). Nonunique invulnerability: Singular versus distributional probabilities and unrealistic optimism in comparative risk judgments. Organizational Behavior \& Human Decision Processes, 67, 229-245.

NeUTHALER, H. (1992). Moral judgments and the compatibility principle. Unpublished undergraduate thesis, Department of Psychology, Princeton University.
Nisbett, R. E., Caputo, C., Legant, P., \& Maracek, J. (1973). Behavior as seen by the actor and as seen by the observer. Journal of Personality \& Social Psychology, 27, 154-164.

PAYNE, J. W. (1982). Contingent decision behavior. Psychological Bulletin, 92, 382-402.

Pennington, N., \& Hastie, R. (1988). Explanation-based decision making: The effects of memory structure on judgment. Journal of Experimental Psychology: Learning, Memory, \& Cognition, 14, 521 533.

Prentice, D. A. (1990). Familiarity and differences in self- and otherrepresentation. Journal of Personality \& Social Psychology, 59, 369383.

Proctor, R. W., \& REEve, T. G. (Eds.) (1990). Stimulus-response compatibility: An integrated perspective. Amsterdam: North-Holland.

Sande, G. N., Goethals, G. R., \& RadlofF, C. E. (1988). Perceiving one's own traits and others': The multifaceted self. Journal of Personality \& Social Psychology, 54, 13-20.

SHAFIR, E. (1993). Choosing versus rejecting: Why some options are both better and worse than others. Memory \& Cognition, 21, 546-556.

ShafiR, E. (1995). Compatibility in cognition and decision. In J. R. Busemeyer, R. Hastie, \& D. L. Medin (Eds.), Decision making from the perspective of cognitive psychology (pp. 247-274). New York: Academic Press.

ShafiR, E., Simonson, I., \& TVERSKy, A. (1993). Reason-based choice. Cognition, 49, 11-36.

SLovic, P. (1990). Choice. In D. Osherson \& E. Smith (Eds.), An invitation to cognitive science (Vol. 3, pp. 89-116). Cambridge, MA: MIT Press.

Slovic, P., Griffin, D., \& TVERSKY, A. (1990). Compatibility effects in judgment and choice. In R. Hogarth (Ed.), Insights in decision making: Theory and applications (pp. 5-27). Chicago: University of Chicago Press.

SNyder, M., \& CANTor, N. (1979). Testing hypotheses about other peopie: The use of historical knowledge. Journal of Experimental Social Psychology, 15, 330-342.

SNYDER, M., \& SWANN, W. B. (1978). Hypothesis-testing processes in social interaction. Journal of Personality \& Social Psychology, 36, 1202-1212.

TAYLOR, S. E., \& Brown, J. D. (1988). Illusion and well-being: A social psychological perspective on mental health. Psychological Bulletin, 103, 193-210.

TETLOCK, P. E. (1992). The impact of accountability on judgment and choice: Toward a social contingency model. In M. P. Zanna (Ed.), Advances in experimental social psychology (Vol. 25, pp. 331-376). New York: Academic Press.

TVERSKY, A., \& KahNEMAN, D. (1973). Availability: A heuristic for judging the frequency and probability. Cognitive Psychology, 5, 207232.

TVERSKY, A., \& KahNeman, D. (1986). Rational choice and the framing of decisions. Journal of Business, 59, 251-278.

TVersky, A., Sattath, S., \& Slovic, P. (1988). Contingent weighting in judgment and choice. Psychological Review, 95, 371-384.

\section{NOTES}

1. Occasional departures, of course, can be envisioned, particularly where different contexts are contemplated-for example, a person who is cooperative at work but competitive in sports.

2. The subjects left a number of comparisons unanswered, particularly when they had not heard of at least one personage in a pair. Of 1,800 possible comparisons, 1,129 were carried out. (Note that selectivity on the part of subjects is more likely to weaken the effect than to exacerbate it.) Because the effect relies on differential familiarity, an even cleaner test would discard those judgments made by respondents who reported being entirely unfamiliar with a personage under consideration or who reported being significantly more familiar with the designated impoverished than with the enriched personage. When these judgments are discarded, the observed effect is strengthened, yielding 
average sums for enriched and impoverished personages of $110 \%$ and $90 \%$, respectively $(p<.005)$.

3. All Princeton undergraduates are assigned to, and initially meet with, a resident advisor at the beginning of their 1 st year. Most students have little interaction with this person throughout the remainder of their 4 years.

4. Three additional pairs of actor names were used but then dropped from all the analyses. This is because the actors were listed along with a recent role they played, which created confusion and led many subjects to refer to the role, rather than to the actor. One respondent, for example, noted that "Patch got a friend killed for not being cautious" when explaining the choice of Robin Williams (in the role of Patch Adams). It is worth noting that the results reported below remain statistically significant (albeit weakened) when these pairs are included
5. In $15 \%$ of the responses in the present transparent version, the same option was selected for both opposite adjectives in a pair. Of these, $68 \%$ of the respondents chose themselves for both adjectives in a pair, and $32 \%$ chose their RA. Fewer subjects were used in this test than in the original analysis of Study 3. The difference in significance levels, however, cannot be attributed to the number of subjects. The present effect size, using the same number of subjects as that in Study 3, would still yield nonsignificant results $(z=0.74)$.

(Manuscript received January 5, 1999; revision accepted for publication July 27,1999 .) 